\title{
PENGARUH AKTIVITAS PERLINDUNGAN KAKI TERHADAP SENSASI PROTEKSI DAN RANGE OF MOTION KAKI PADA PENDERITA DIBETES MELITUS TIPE 2 DENGAN NEUROPATI PERIFER
}

\author{
Istiroha $^{1}$, Elyana Asnar STP ${ }^{2}$, Harmayetty ${ }^{3}$
}

1. Mahasiswa Program Magister Keperawatan, Fakultas Keperawatan Universitas Airlangga, Kampus C Mulyorejo, email: istiroha08@gmail.com

2. Departemen Ilmu Faal, Universitas Airlangga

3. Departemen Keperawatan Medikal Bedah, Universitas Airlangga

\begin{abstract}
The somatosensory deficit in diabetic peripheral neuropathy can include loss of movement perception at the ankle joint and loss of plantar cutaneous sensation. Foot protection activities can maintain balance and strength of the legs. The purpose of this study was to determine the effect of foot protection activity on foot sensation, ROM of ankle and $1^{\text {st }}$ MTP joint in type 2 diabetes with peripheral neuropathy. This research used pretest-postest control group design. Subjects used are patients with type 2 diabetes outpatient in RSUD Ibnu Sina Gresik as many as 28 patients. The subjects of the treatment group were given foot protection activity for 30 minutes, 2 times each week for 4 weeks. The variables measured were sensation of protection, ROM of ankle and $1^{\text {st }}$ MTP joint. The instruments used are Semmes-Weinstein Monofilament Test (SWMT) $10 \mathrm{~g}$ and goniometer. After 4 weeks of treatment, paired t test showed an increase in foot protection sensation, ROM of ankle and 1 st MTP joint in the treatment group with $p$ value $S W M T=0,000$, ROM of ankle dorsiflexion $p=0,005$, plantarflextion ankle $p=0,006$, ankle eversion $p=0.002$, ankle inversion $p=$ $0,000,1^{\text {st }}$ MTP flexion $p=0.009$ and $1^{\text {st }}$ MTP extension $p=0.002$. The independent $t$ test value of foot protection sensation, ROM of ankle and 1st MTP joint between treatment and control group also showed significant differences in treatment group than control group. This study shows the effect of foot protection activity on the sensation of foot protection and ROM of the foot joint so that it can be used as an alternative intervention to prevent diabetic foot ulcers either independently or in health services.
\end{abstract}

Keywords: foot protection, sensation, ROM

Abstrak: Gangguan somatosensori pada neuropati diabetik meliputi hilangnya persepsi pergerakan sendi ankle dan hilangnya sensasi proteksi kaki. Aktivitas perlindungan kaki dapat menjaga keseimbangan dan kekuatan tungkai. Tujuan penelitian adalah untuk untuk mengetahui pengaruh aktivitas perlindungan kaki terhadap sensasi proteksi kaki, ROM sendi ankle dan $1^{\text {st }}$ MTP pada penderita DM tipe 2 dengan neuropati perifer. Penelitian ini mengunakan desain control group pretest-postest. Subjek yang digunakan adalah penderita DM tipe 2 di Poli Penyakit Dalam RSUD Ibnu Sina Gresik sebanyak 28 orang. Subjek kelompok perlakuan diberikan aktivitas perlindungan kaki selama 30 menit, sebanyak 2 kali setiap minggu selama 4 minggu. Variabel yang diukur adalah sensasi proteksi, ROM sendi ankle dan $1^{\text {st }}$ MTP. Instrumen yang digunakan adalah Semmes-Weinstein Monofilament Test (SWMT) $10 \mathrm{~g}$ dan goniometer. Setelah 4 minggu perlakuan, uji paired $t$ test menunjukkan terdapat peningkatan pada sensasi proteksi kaki, ROM sendi ankle dan $1^{\text {st }}$ MTP pada kelompok perlakuan dengan nilai $\mathrm{p} S W M T=0,000, \mathrm{ROM}$ ankle dorsofleksi $\mathrm{p}=0,005$, ankle plantarfleksi $\mathrm{p}=0,006$, ankle eversi $\mathrm{p}=0,002$, ankle inversi $\mathrm{p}=0,000,1^{\text {st }}$ MTP fleksi $\mathrm{p}=0,009$ dan $1^{\text {st }}$ MTP ekstensi $\mathrm{p}=0,002$. Hasil uji independent $t$ test nilai sensasi proteksi kaki, ROM sendi ankle dan $1^{\text {st }}$ MTP antara kelompok perlakuan dan pembanding juga menunjukkan perbedaan yang signifikan pada kelompok perlakuan. Penelitian ini menunjukkan adanya pengaruh aktivitas perlindungan kaki terhadap sensasi proteksi kaki dan ROM kaki sehingga 
intervensi ini dapat digunakan sebagai alternatif tindakan pencegahan ulkus kaki diabetikum baik secara mandiri maupun dalam pelayanan kesehatan.

\section{Kata kunci : perlindungan kaki, sensasi, ROM}

\section{PENDAHULUAN}

Neuropati perifer merupakan salah satu komplikasi yang paling umum terjadi pada penderita diabetes melitus (DM) (Davies, et al., 2006). Neuropati perifer biasanya tidak terdeteksi dari awal tetapi menjadi faktor penyebab utama terjadinya ulkus kaki (Shilling, 2002). Sebanyak 75 dari 79 penderita DM tipe $2(94,9 \%)$ yang belum terjadi ulkus mengalami neuropati perifer diabetikum (diabetes peripheral neuropathy) (Suyanto \& Susanto, 2016). Penelitian lain menunjukkan dari 34 pasien DM yang belum terjadi ulkus diabetikum 16 diantaranya mengalam neuropati sensorik dan 8 pasien mengalami neuropati motorik (Purwanti, 2013).

Gangguan somatosensori pada neuropati diabetik dapat termasuk hilangnya fungsi otot tungkai bawah, hilangnya persepsi pergerakan sendi ankle dan hilangnya sensasi proteksi kaki. (Chatchawan, et al., 2015; van Deursen, et al., 1998; van Deursen, et al., 1999). Neuropati sensorik akan menyebabkan penurunan sensasi proteksi, meliputi nyeri, suhu, dan sentuhan getaran sehingga penderita DM akan mudah mengalami trauma tanpa terasa yang berlanjut pada terjadinya ulkus diabetikum (Endriyanto, 2012; Frykberg, et al., 2006). Neuropati motorik mengakibatkan atrofi pada otot crural anterior atau otot intrisik yang akan menyebabkan deformitas kaki seperti foot drop, pergelangan kaki bengkok (equinus), dan kelainan bentuk jari-jari kaki. Pergelangan kaki yang bengkok (ankle equinus) dengan luas gerak sendi yang terbatas umum terjadi pada pasien DM dengan neuropati yang dapat menyebabkan atrofi otot crural anterior. Penurunan luas gerak sendi menyebabkan penekanan pada kaki yang abnormal sehingga mengakibatkan ulkus kaki (Chatchawan, et al., 2015).
Aktivitas perlindungan kaki merupakan serangkaian aktivitas untuk kesehatan kaki yang diberikan oleh perawat gerontik di klinik perawatan kaki lansia di Texas (Pattillo, 2004). Kegiatan dalam program aktivitas perlindungan kaki meliputi pengkajian tentang gaya berjalan dan keseimbangan kaki, pemeriksaan kaki, perendaman kaki, perawatan kuku, pijat kaki, edukasi perawatan diri, serta latihan kaki dan jari-jari kaki (Patillo, 2004).

Kombinasi antara perawatan kaki, latihan kaki dan jari-jari, serta pijat kaki akan meningkatkan pengatahuan dan kesadaran akan pentingnya merawat kaki secara rutin, menigkatkan kekuatan jari-jari kaki, mencegah ketidaknyamanan pada kaki, menurunkan resiko jatuh, dan meningkatkan relaksasi pada kaki (Pattillo, 2004; Hayes \& Cox, 1999) sebagai akibat dari perbaikan range of motion dan sensasi proteksi kaki. Penelitiann sebelumnya menunjukkan dengan memberikan Thai foot massage selama 2 minggu menunjukkan adanya peningkatan pada time up and go (TUG), range of motion (ROM) pada kaki, dan sensasi proteksi pada kaki penderita DM dengan neuropati (Chatchawan, et al., 2015). Namun, belum ada penelitian tentang efektifitas aktivitas perlindungan kaki terhadap sensasi proteksi dan ROM sendi ankle serta ROM sendi metatarsophalangeal yang pertama $\left(1^{\text {st }}\right.$ MTP) pada penderita DM tipe 2 dengan neuropati diabetik. Untuk itu, tujuan penelitian ini adalah untuk mengetahui pengaruh aktivitas perlindungan kaki terhadap sensasi proteksi kaki dan ROM sendi ankle serta ROM sendi $1^{\text {st }}$ MTP pada penderita DM tipe 2 dengan neuropati diabetik.

\section{METODE}

Penelitian ini menggunakan Quasy Experiment yang menggunakan desain 
control group pretest-postest. Subjek penelitian yang digunakan adalah penderita DM tipe 2 yang menjalani rawat jalan di Poli Penyakit Dalam RSUD Ibnu Sina Gresik. Penderita DM tipe 2 yang mengalami neuropati perifer, rutin menggunakan terapi DM dengan jenis yang sama: sulfonilurea (glimepirid) dan buguanid (metformin), kada glukosa darah puasa (1 bulan terakhir) terkontrol (90-130 $\mathrm{mg} / \mathrm{dl}$ ) atau glukosa darah acak < $180 \mathrm{mg} / \mathrm{dl}$ dan bisa berjalan tanpa bantuan menjadi responden dalam penelitian ini. Namun penderita DM tipe 2 yang mengalami ulkus kaki diabetikum dan infeksi pada kaki (selulitis dan vaskulitis), mengalami depresi, khawatir atau cemas dan mengalami komplikasi pada sistem persarafan: stroke dikeluarkan dari penelitian ini.

Setelah pasien bersedia menjadi responden dengan menyutujui inform consent, kemudian pasien akan dipasangkan (matching) sesuai dengan kategori usia (grup 1= usia $<50$ tahun, grup 2= usia 51-60 tahun, dan grup $3=$ usia $>60$ tahun), riwayat merokok (merokok dan tidak merokok), dan lama menderita DM ( $<5$ tahun, 6-10 tahun, dan $>10$ tahun). Selanjutnya sampel akan dibagi ke dalam kelompok perlakuan dan kelompok kontrol secara acak (random).

Etik penelitian pada penelitian ini diberikan oleh komite etik Faklutas Keperawatan Universitas Airlangga.

Penghitungan estimasi besar sampel berdasarkan standar deviasi selisih mean antara kelompok perlakuan dan kontrol pada variabel sensasi proteksi setelah dilakukan Thai foot massage (Chatchawan et al., 2015) kemudian ditambahkan $10 \%$ estimasi besar sampel yang drop out sehingga didapatkan besar sampel adalah 16 orang setiap kelompok. Tetapi, pada pertengahan penelitian terdapat 2 responden yang mengalami drop out pada setiap kelompok sehingga hanya 14 sampel yang mengikuti penelitian sampai akhir.

\section{Intervensi}

Setelah pasien bersedia menjadi responden dengan menyutujui inform consent, kemudian peneliti dan asisten memberikan intervensi aktivitas perlindungan yang mengkombinasikan antara edukasi perawatan kaki, latihan kaki, dan pijat kaki sesuai dengan potokol healthy feet clinic melalui kunjungan rumah.

Peneliti dan asisten menjelaskan dan mendemonstrasikan tentang bagaimana cara merawat kaki. Selanjutnya, peneliti dan asisten mempraktekkan latihan kaki dan jari kaki. Gerakan latihan ini terdiri dari toe raise, toe point, toe curl, golf ball roll, towel curls, dan marble pick up. Selanjutnya intervensi yang diberikan adalah dengan pemijatan kaki kanan dan kiri selama 5-10 menit pada setiap kaki. Kedua kaki dipijat dengan cara manual yakni hanya menggunakan dua tangan dengan teknik back and forth dan ankle rotation (Pattillo, 2004). Pemberian aktivitas perlindungan kaki ini diberikan sebanyak 2 kali setiap minggu selama 4 minggu dan setiap sesi intervensi diberikan selama 30-40 menit.

Responden pada kelompok pembanding melakukan senam kaki diabetik sesuai dengan standart rumah sakit. Gerakan senam kaki yang telah diajarkan petugas rumah sakit disarankan untuk dilakukan responden selama 30 menit, sebanyak 2 kali perminggu selama 4 minggu di rumah mereka masing-masing. Peneliti juga memberikan leaflet gerakan senam kaki untuk mengingatkan mereka kembali tentang gerakan senam kaki diabetik.

\section{Pengukuran}

Hasil penelitian ini diukur sebelum (pre test) dan setelah (postest) intervensi diberikan yaitu pada hari ke 2-3 setelah intervensi terakhir diberikan (4 minggu). Variabel dependen yang diukur adalah sensasi proteksi kaki dan ROM sendi ankle dan $1^{\text {st }}$ MTP. Sensasi proteksi kaki diukur dengan Semmes-Weinstein Monofilament Test (SWMT) 10g. Jika jawaban pasien salah artinya titik tersebut merupakan titik positif SWMT dan jika setelah diulang 2 kali jawaban tetap salah maka pada area tersebut mengalami kehilangan sensasi proteksi kaki (British Columbia Provincial Nursing Skin and Wound Committee, 2012). Hasil rata-rata titik posistif SWMT pada ke dua kaki menjadi data untuk dianalisis. 
Aktif ROM sendi ankle and $1^{\text {st }}$ MTP pada ke dua kaki diukur dengan goniometer.

Data yang digunakan dalam penghitungan statistik adalah data rerata. Hasil pengukuran nilai SWMT dan ROM sendi ankle dan $1^{\text {st }}$ MTP kaki kanan dan kiri dihitung kemudian dirata-rata. Data pretest dan postest pada ke dua kelompok dianalisa dengan menggunakan uji paired $t$ test, sedangkan data perbandingan post test antara ke dua kelompok dianalisa dengan uji indpendent $t$ test dengan nilai signifikasi $\mathrm{p}<0,05$.

\section{HASIL DAN PEMBAHASAN}

Hasil observasi karakteristik responden berdasarkan jenis kelamin, usia, pendidikan, pekerjaan, durasi penyakit DM Tipe 2, riwayat HT, dan riwayat merokok di Poli Penyakit Dalam RSU Ibnu Sina Gresik pada bulan April-Mei 2017 pada ke dua kelompok dapat dilihat pada Table 1. Tabel 1 menunjukkan bahwa karakteristik demografi antara kelompok perlakuan dan pembanding tidak jauh berbeda, hal ini dibuktikan dengan uji homogenitas dengan nilai $p>0,05$ artinya data karakteristik responden baik pada kelompok perlakuan dan pembanding tidak bervariasi (homogen). Pada Tabel 2 diketahui bahwa nilai rata-rata SWMT pada kelompok perlakuan meningkat setelah diberikan intervensi dengan nilai $\mathrm{p}=0,000$. Jika dibandingkan dengan kelompok pembanding maka nilai rata-rata SWMT setelah 4 minggu signifikan pada kelompok perlakuan dengan nilai p 0,000. Nilai ROM ankle pada kelompok perlakuan rata-rata meningkat setelah diberikan intervensi (ankle dorsofleksi $\mathrm{p}=0,005$, ankle plantarfleksi $\mathrm{p}=0,006$, ankle eversi $\mathrm{p}=0,002$, ankle inversi $\mathrm{p}=0,000$ ). Setelah 4 minggu nilai rata-rata $\mathrm{ROM}$ ankle pada kelompok perlakuan lebih signifikan meningkat dibandingan dengan kelompok pembanding. Begitupula pada ROM $1^{\text {st }}$ MTP yang pertama, nilai rata-rata post test pada kelompok perlakuan meningkat secara signifikan $\left(1^{\text {st }}\right.$ MTP fleksi $\mathrm{p}=0,009$ dan $1^{\text {st }}$ MTP ekstensi $\mathrm{p}=0,002)$. Perbandingan antara dua kelompok menunjukkan kelompok perlakuan lebih signifikan meningkat dibandingkan dengan kelompok pembanding

Tabel 1. Karakteristik demografi

\begin{tabular}{|c|c|c|c|c|c|}
\hline \multirow[t]{2}{*}{$\begin{array}{c}\text { Karakteristik } \\
\text { Responden }\end{array}$} & \multicolumn{2}{|c|}{$\begin{array}{c}\begin{array}{c}\text { Kelompok Perlakuan } \\
(n=14)\end{array} \\
\text { Jumlah } \\
\end{array}$} & \multicolumn{2}{|c|}{$\begin{array}{c}\begin{array}{c}\text { Kelompok Pembanding } \\
(\mathrm{n}=14)\end{array} \\
\text { Jumlah }\end{array}$} & \multirow{2}{*}{$\begin{array}{c}\text { Uji } \\
\text { Homogenitas } \\
(p \text { value })\end{array}$} \\
\hline & n & $\%$ & $\mathbf{n}$ & $\%$ & \\
\hline \multicolumn{6}{|l|}{ Jenis kelamin } \\
\hline Laki-laki & 4 & 28,6 & 4 & 28,6 & \multirow[t]{3}{*}{1,000} \\
\hline Perempuan & 10 & 71,4 & 10 & 71,4 & \\
\hline Total & 14 & 100,0 & 14 & 100,00 & \\
\hline \multicolumn{6}{|l|}{ Usia } \\
\hline$<50$ tahun & 1 & 7,1 & 2 & 14,3 & \multirow[t]{4}{*}{0,207} \\
\hline 51-60 tahun & 9 & 64,3 & 8 & 57,1 & \\
\hline$>60$ tahun & 4 & 28,6 & 4 & 28,6 & \\
\hline Total & 14 & 100,0 & & 100,0 & \\
\hline \multicolumn{6}{|l|}{ Pendidikan } \\
\hline Perguruan tinggi & 4 & 28,6 & 4 & 28,6 & \multirow[t]{6}{*}{0,384} \\
\hline SMA & 5 & 35,7 & 2 & 14,3 & \\
\hline SMP & 3 & 21,4 & 4 & 28,6 & \\
\hline SD & 4 & 28,6 & 3 & 21,4 & \\
\hline Tidak sekolah & 0 & 0,0 & 1 & 7,1 & \\
\hline Total & 14 & 100,0 & 14 & 100,0 & \\
\hline \multicolumn{6}{|l|}{ Pekerjaan } \\
\hline Tidak bekerja & 7 & 50,0 & 5 & 35,7 & \multirow[t]{6}{*}{0,743} \\
\hline Pensiunan & 3 & 21,4 & 2 & 14,3 & \\
\hline PNS & 0 & 0,0 & 1 & 7,1 & \\
\hline Wiraswasta & 1 & 7,1 & 3 & 21,4 & \\
\hline Lain-lain & 3 & 21,4 & 3 & 21,4 & \\
\hline Total & 14 & 100,0 & 14 & 100,0 & \\
\hline \multicolumn{5}{|c|}{ Durasi menderita DM Tipe 2} & \\
\hline
\end{tabular}




\begin{tabular}{|c|c|c|c|c|c|}
\hline$<5$ tahun & 5 & 35,7 & 6 & 42,9 & 0,228 \\
\hline 5-10 tahun & 5 & 35,7 & 2 & 14,3 & \\
\hline$>10$ tahun & 4 & 28,6 & 6 & 42,9 & \\
\hline Total & 14 & 100,0 & 14 & 100,0 & \\
\hline \multicolumn{6}{|c|}{ Riwayat hipertensi } \\
\hline Ya & 6 & 42,9 & 7 & 50,0 & \multirow[t]{3}{*}{0,607} \\
\hline Tidak & 8 & 57,1 & 7 & 50,0 & \\
\hline Total & 14 & 100,0 & & 100,0 & \\
\hline \multicolumn{6}{|c|}{ Kebiasaan merokok } \\
\hline Beresiko & 0 & 0,0 & 0 & 0,0 & \multirow[t]{3}{*}{-} \\
\hline Tidak Beresiko & 14 & 100,0 & 14 & 100,0 & \\
\hline Total & 14 & 100,0 & 14 & 100,0 & \\
\hline
\end{tabular}

Tabel 2 menunjukkan bahwa setelah diberikan aktivitas perlindungan kaki selama 4 minggu nilai positif SWMT pada kelompok perlakuan menurun dari 3,64 menjadi 2,35 artinya terdapat 3-4 titik kaki yang tidak respons terhadap sensasi monofilamen 10 gr menurun menjadi 2-3 titik. Sedangkan pada kelompok pembanding nilai SWMT tidak menunjukkan penurunan yang signifikan.

Aktivitas perlindungan kaki yang mengkombinasikan tiga intervensi: perawatan kaki, latihan kaki, dan pijat kaki akan meningkatkan sensitivitas kaki karena terjadi perbaikan perfusi darah di kaki. Hasil penelitian ini sejalan dengan penelitian sebelumnya yaitu Calle, Pascual, dan Duran (2001) yang menyatakan bahwa kelompok responden yang tidak melakukan perawatan kaki 13 kali lebih beresiko terjadi ulkus diabetik dibandingkan dengan kelompok responden yang melakukan perawatan kaki secara teratur dengan cara menjaga sirkulasi darah kaki.

Tabel 2. Nilai perbandingan nilai pre test dan post test setelah intervensi pada kelompok perlakuan dan pembanding

\begin{tabular}{|c|c|c|c|c|}
\hline Variabel & Kelompok & $\begin{array}{c}\text { Rerata nilai } \\
\text { pretest }\end{array}$ & $\begin{array}{c}\text { Rerata nilai } \\
\text { postest }\end{array}$ & p value \\
\hline \multirow[t]{2}{*}{ Nilai positif SWMT } & Perlakuan & 3,64 & 2,35 & \multirow{2}{*}{0,000} \\
\hline & Pembanding & 4,50 & 4,35 & \\
\hline \multirow[t]{2}{*}{ ROM ankle dorsofleksi } & Perlakuan & 15,86 & 17,96 & \multirow{2}{*}{0,003} \\
\hline & Pembanding & 17,64 & 16,93 & \\
\hline \multirow{2}{*}{$\begin{array}{l}\text { ROM } \\
\text { plantarfleksi }\end{array}$} & Perlakuan & 32,04 & 40,29 & \multirow{2}{*}{0,029} \\
\hline & Pembanding & 33,89 & 35,21 & \\
\hline \multirow[t]{2}{*}{ ROM ankle eversi } & Perlakuan & 11,89 & 14,07 & \multirow{2}{*}{0,002} \\
\hline & Pembanding & 13,25 & 13,1 & \\
\hline \multirow[t]{2}{*}{ ROM ankle inversi } & Perlakuan & 22,93 & 29,18 & \multirow{2}{*}{0,000} \\
\hline & Pembanding & 24,61 & 24,5 & \\
\hline \multirow{2}{*}{ ROM $1^{\text {st }}$ MTP fleksi } & Perlakuan & 32,5 & 36,5 & \multirow{2}{*}{0,016} \\
\hline & Pembanding & 32,11 & 30,11 & \\
\hline \multirow[t]{2}{*}{ ROM $1^{\text {st }}$ MTP ekstensi } & Perlakuan & 38,21 & 50,43 & \multirow{2}{*}{0,003} \\
\hline & Pembanding & 39,04 & 38,61 & \\
\hline
\end{tabular}

Penelitian Priyanto (2012) juga menunjukkan lansia yang telah diberikan senam kaki memiliki sensitivitas kaki yang lebih baik setelah diberikan senam kaki selama 4 minggu dengan $\mathrm{p}$ value 0,000 . Penurunan aliran darah sebagai akibat perubahan viskositas memacu meningkatkan kompensasinya dalam tekanan perfusi sehingga akan meningkatkan transudasi melalui kapiler dan selanjutnya akan meningkatkan viskositas darah. Iskemia perifer yang terjadi lebih lanjut disebabkan peningkatan afinitas hemoglobin terglikolasi terhadap 
molekul oksigen (Mathes, 2002; Arifin, 2013). Hal tersebut sebagai pemicu terbentuknya mikrotrombosis dan hipoksia jaringan sehingga mengakibatkan transport aksonal terganggu dan penurunan aktivitas $\mathrm{Na}+/ \mathrm{K}+$ ATP ase, hal inilah yang dapat memperlambat viskositas konduksi saraf (Prasetyo, 2010; Arifin, 2013). Pemberian rangsangan berupa olahraga atau latihan kaki dapat membangkitkan potensial aksi sehingga mengakibatkan terjadinya depolarisasi yang mengakibatkan peningkatan aktivitas $\mathrm{Na}+\mathrm{K}+\mathrm{ATP}$ ase, transport aksonal mengalami perbaikan, pasien merasakan sensasi sensorik/respon sensorik. Dengan kata lain, ujung-ujung saraf penderita mengalami perbaikan konduksi dan kembali sensitif dalam proteksi terhadap kondisi yang beresiko, yang terdeteksi dengan pemeriksaan sensasi proteksi dengan menggunakan monofilamen $10 \mathrm{~g}$.

Pemberian pijat kaki juga memberikan pengaruh yang signifikan pada sensasi proteksi kaki. Sejalan dengan penelitian sebelumnya, Harmaya, et al. (2014) menunjukkan bahwa terdapat pengaruh masase kaki terhadap sensasi proteksi kaki pasien DM tipe II dengan gejala diabetic peripheral neuropathy di Puskesmas 1 Denpasar Utara. Selain itu, hasil penelitian Mulyati (2012) juga menunjukkan bahwa dengan pemberian pijat kaki secara manual selama 12 hari untuk penderi DM sensasi proteksi kaki responden meningkat.

Pemberian pijat kaki dapat membantu melancarkan dan memperbaiki sirkulasi darah pada kaki. Penekanan yang dilakukan melalui teknik pijat mengakibatkan vasodilatasi pembuluh darah yang melibatkan refleks pada otot di dinding arteriol sehingga pijat dapat memperbaiki sirkulasi darah pada area yang di berikan pijat. Sirkulasi darah yang lancar yang membawa oksigen dan nutrisi menuju jaringan dan sel saraf yang akan mempengaruhi proses metabolisme sel Schwann sehingga fungsi akson dapat dipertahankan. Fungsi sel saraf yang optimal pada pasien DM akan mempertahankan fungsi sensasi kakinya (Premkumar, 2004; Cassar, 2004; Harmaya, et al., 2012). Mekanisme ini dibuktikan dengan hasil dalam penelitian ini bahwa sebagian besar (12 responden) mengalami penurunan jumlah titik yang tidak merespon terhadap sensasi monofilamen $10 \mathrm{~g}$.

Hasil pengukuran akhir setelah dilakukan intervensi aktivitas perlindungan kaki pada kelompok perlakuan menunjukkan peningkatan pada luas gerak sendi ankle dorsofleksi, ankle plantarfleksi, ankle eversi, ankle inversi, $1^{\text {st }}$ MTP fleksi, dan $1^{\text {st }}$ MTP ekstensi. Peningkatan luas gerak sendi yang terjadi pada responden dapat dilihat pada tabel 2. Pada pengukuran akhir didapatkan mobilitas sendi ankle dan $1^{\text {st }}$ MTP berada pada kategori normal yang mana sendi dapat bergerak penuh, dapat melawan gravitasi dan tahanan maksimal, dan kategori good yang mana sendi dapat bergerak penuh, mampu melawan gravitasi, dan tahanan sedang.

Pemberian edukasi perawatan kaki bertujuan untuk mengurangi resiko berkembangnya gangguan kaki pada penderita DM. Sejalan dengan hasil penelitian Vatankhah et al. (2009) bahwa dengan memberikan intervensi edukasi perawatan kaki penderita DM tipe 2 dapat meningkatkan pengetahuan dan kemampuan mereka tentang perawatan kaki (foot care) DM serta dapat menigkatkan motivasi dan merubah perilaku penderita DM tipe 2 untuk lebih perhatian terhadap kaki mereka (Vatankhah et al., 2009).

Latihan kaki dan jari kaki pada aktivitas perlindungan terdiri dari gerakan toe raise, toe point, toe curl, golf ball roll, towel curls, marble pick up yang banyak melibatkan pergerakan sendi ankle dan jari-jari kaki. Menurut Jenkins (2006) dengan adanya pergerakan pada persendian akan menyebabkan terjadinya peningkatan aliran darah ke dalam kapsula sendi dan memberikan nutrisi yang memungkinkan tulang untuk bergerak dengan lancar dan tanpa rasa sakit atau ketidaknyamanan.

Penelitian yang hampir sama dilakukan oleh Zimny, Schatz, dan Pfohl (2004) secara 
acak dan terkontrol tentang efek dari program latihan rumah enam minggu. Program latihan terdiri dari 5-10 menit jalan pemanasan, heel raises, toe raises, dan towel exercises (dorsofleksi, eversi, dan inversi) yang dilakukan tiga kali seminggu selama enam minggu. Hasil penelitian tersebut didapatkan hanya ROM plantarfleksi yang signifikan terhadap progam latihan tetapi tidak ada perubahan signifikan dalam gaya berjalan.

Pemberian pijat kaki dengan teknik penekanan dalam yang dikombinasikan dengan peregangang kaki dan tungkai akan meningkatkan LGS dan sensasi proteksi kaki. Pijat kaki akan meningkatkan sirkulasi darah lokal dan merangsang sistem somatosensory, termasuk reseptor-reseptor yang ada di kaki (Vaillant et al., 2009; Chatchawan et al., 2015). Efek ini bisa mengurangi neuropati dengan merubah distribusi tekanan kaki, sistem propriosetif, kekuatan otot, pergerakan sendi, dan tarikan otot. Teknik penekanan dalam secara langsung (direct deep pressure) dapat meningkatkan peregangan jaringan kapsular dan jaringan ligamen (Perry, 2006; Chatchawan et al., 2015). Selain itu, teknik tersebut akan merangsang mekanoreseptor sendi yang akan meningkatkan fungsi neuromuskular otot-otot keseimbangan sendi. Mobilisasi sendi juga dapat meningkatkan fleksibilitas sendi dan kontrol postural. Hal ini dibuktikan oleh penelitian Chatchawan et al., (2015) yang mana dengan pemberian pijat kaki dengan jenis pijat tailan sebanyak $3 \mathrm{kali} /$ minggu selama 2 minggu dapat meningkatkan time and go (TUG), berdiri dengan satu kaki, ROM, dan nilai monofilamen $10 \mathrm{~g}$.

\section{SIMPULAN}

Aktivitas perlindungan kaki dapat meningkatkan sensasi proteksi kaki dan ROM kaki.

\section{DAFTAR PUSTAKA}

Aalaa M, Malazy OT, Sanjari M, Peimani M, Tehrani MRM (2012), Nurses' role in diabetic foot prevention and care; a review, Journal of Diabetes \&
Metabolic Disorders, 11, 24 diakses 6 November 2016

American Orthopedic Foot and Ankle Society (2017), How to Keep Your Feet Flexible, diakses tanggal 18 Januari 2017 jam 10:16 WIB

Arifin H (2013), Pengaruh Senam Kaki Diabetik Terhadap Respon Neuropati Pada Pasien Diabetes Melitus Tipe 2 Non Ulkus Di Poliklinik Endokrin Rsup. Dr. Wahidin SudirohusodoMakassar, Skripsi, Universitas Hasanuddin, Makassar.

British Columbia Provincial Nursing Skin and Wound Committee (2012), Procedure: Monofilament Testing for Loss of Protective Sensation of Diabetic/Neuropathic Feet for Adults \& Children.

Chatchawan U, Eungpinichpong W, Plandee P, Yamauchi J (2015), Effects of Thai Foot Massage on Balance Performance in Diabetic Patients with Peripheral Neuropathy: A Randomized Parallel-Controlled Trial, Medical Science Monitor Basic Reasearch, 21, 68-75.

Davies M, Brophy S, Williams R, Taylor A (2006), The Prevalence, Severity, and Impact of Painful Diabetic Peripheral Neuropathy in Type 2 Diabetes, Diabetes Care, 29, 1518-1522 diakses tanggal 4 Januari 2017,.

Dixit S, Maiya AG, Shastry BA (2014), Effect of aerobic exercise on peripheral nerve functions of population with diabetic peripheral neuropathy in type 2 diabetes: A single blind, parallel group randomized controlled trial, Journal of Diabetes and Its Complications, 28, 332-339.

Endriyanto E, Hasneli Y, Dewi YI (2012), Efektifitas Senam Kaki Diabetes Melitus dengan Koran Terhadap Tingkat Sensitivitas Kaki Pada Pasien DM Tipe 2, Jurnal Universitas Riau.

Frygberk RG, Armstrong DG, Driver VR, Gurini JM, Kravitzs SR, Vanore JV 
(2006), Diabetic Foot Disorders A Clinical Practice Giudelines. The Journal of Foot\& Ankle Surgery, 45, 5.

Harmaya, Sukawana IW, Lestari MPL (2014), Pengaruh Masase Kaki Terhadap Sensasi Proteksi Pada Kaki Pasien Diabetes Melitus Tipe II dengan Diabetic Peripheral Neuropathy Tahun 2014, jurnal PSIK FK Universitas Udayana.

Hayes J \& Cox C (1999). Immediate effects of a five-minute foot massage on patient in ritical care. Intensive and Critical Care Nursing, 15 (2), 77-82.

Jenkis L (2005), Maximizing Range of Motion in Older Adults. The Journal on Active Aging, 50-55.

Mecagni C, Smith JP, Roberts KE et al., (2000), Balance and ankle range of motion in community-dwelling women aged 64 to 87 years: a correlational study. Phys Ther, 80(10): 1004-11

Pattillo M (2004), Therapeutic and Healing Foot Care: A Healthy Feet Clinic for Older Adults, Journal of Gerontological Nursing, 30, 12, 2532.

Priyanto S (2012), Pengaruh Senam Kaki Terhadap Sensitivitas Kaki dan Kadar Gula Darah pada Agregat Lansia Diabetes Melitus di Magelang, Tesis, Universitas Indonesi, Jakarta

Purwanti OS (2013), Analisis Faktor-Faktor Resiko Terjadi Ulkus Kaki pada Pasien Diabetes Mellitus di RSUD Dr. Moewardi, Tesis dipublikasikan, Universitas Indonesia, Jakarta.

Ritzline PD, Swanson J (2010), The Effects of A Home Exercise Program on Ankle Range of Motion and Step Length in People With Type 2 Diabetes: A Blinded Cross-Over Design Pilot Study. Presented at the annual meeting of the American
Physical Therapy Association, Boston.

Shilling F (2003), Foot Care in Patients with Diabetes, Nursing Standard, 17, 23, 61-68.

Subekti I (2007), Hidup Sehat dengan Diabetes. Jakarta: Balai Penerbit.

Suyanto \& Susanto A (2016), FaktorFaktor yang Berhubungan dengan Kejadian Neuropati Perifer Diabetik, Nursecope Jurnal Keperawatan dan Pemikiran Ilmiah, 2, 6, 1-7 diakses tanggal 3 November 2016.

Vaillant J, Rouland A, Martigne $\mathrm{P}$ et al (2009), Massage and mobilization of the feet and ankles in elderly adults: effect on clinical balance performance. Man Ther, 14(6): 66164

Vaillant J, Vuillerme N, Janvey A et al (2008), Effect of manipulation of the feet and ankles on postural control in elderly adults. Brain Res Bull, 75(1): $18-22$

van Deursen RW, Sanchez MM, Ulbrecht JS et al. (1998), The role of muscle spindles in ankle movement perception in human subjects with diabetic neuropathy. Exp Brain Res, 120(1): 1-8

van Deursen RW, Simoneau GG (1999), Foot and ankle sensory neuropathy, proprioception, and postural stability. J Orthop Sports Phys Ther, 29(12): 718-26

Vatankhah N, Khamseh ME, Noudeh YJ, Aghili R, Baradaran HR, Haeri NS (2009), The effectiveness of foot care education on people with type 2 diabetes in Tehran, Iran, Primary Care Diabetes, 3, 73-77 diakses tanggal 8 November 2016 ,

Zimny S, Schatz H, Pfohl M, (2004), The Role of Limited Joint Mobility in Diabetic Patients With an At-Risk Foot, Diabetes Care, 27, 4: 942-946. 